\title{
CUSTO COMPARATIVO DO TRATAMENTO DE FERIDAS ${ }^{1}$
}

\author{
COMPARATIVE COST OF WOUND TREATMENT \\ COSTE COMPARATIVO DEL TRATAMIENTO DE HERIDAS
}

\author{
Eline Lima Borges ${ }^{2}$ \\ Flávia Sampaio Latini Gomes ${ }^{3}$ \\ Sandra Regina da Costa Saar ${ }^{4}$
}

RESUMO: Este estudo compara o custo do curativo tradicional e o do preconizado pelo protocolo do setor de Estomaterapia do HC/UFMG no tratamento de diversos tipos de feridas. Ao final do trabalho, foi possivel concluir que o custo do último é inferior ao do primeiro e que a frequêencia na troca do curativo tradicional constitui fator de maior significância na elevaçăo de seu custo.

PALAVRAS-CHAVE: feridas, custo, curativo, limpeza, cobertura.

\section{INTRODUÇÃO}

Ao propormos mudanças em um projeto, a primeira indagaçăo que precisamos esclarecer é: qual o seu custo? A realidade nos impőe pensar assim, quer no âmbito doméstico, quer no do trabalho. Os hospitais năo fogem a esta regra, sendo este um dos principios da administraçăo contemporânea - diminuir custos sem prejuizo do benefício.

Embora seja um fator limitante na aquisiçăo do material utilizado na confecçăo de curativos, pouca atençăo é dada ao custo. Saliente-se que năo se deve considerar apenas o custo vinculado ao material, mas também o que diz respeito ao tempo do profissional, à instituição de saúde levando em conta à "demora na cicatrizaçăo ou às complicaçőes que adiam a recuperaçăo" ( Dealey, 1996) - , ao paciente e à comunidade.

O setor de Estomaterapia do Hospital das Clinicas da Universidade Federal de Minas Gerais (HC/UFMG) foi criado, em 1995, para atender portadores de estomas, fistulas e feridas crônicas. Em 1997, em decorrência da crise enfrentada pelos hospitais universitários, foi suspensa temporariamente a prestaçăo de atendimento.

No segundo semestre de 1998, buscou-se retomar o atendimento e reestruturar o setor de Estomaterapia. Dois docentes do departamento de Enfermagem Básica da Escola de Enfermagem da Universidade Federal de Minas Gerais (EE/UFMG) elaboraram um projeto de extensão direcionado, primeiramente, aos pacientes portadores de feridas crônicas. Após aprovado pelos órgăos competentes, esse projeto foi implantado, com a participaçăo da enfermeira do anexo de Dermatologia do HC/UFMG.

Para sistematizar a assistência, criou-se um protocolo, que preconiza a operacionalizaçăo do setor, a técnica de limpeza das feridas, os parâmetros de avaliaçăo e evoluçăo do paciente

'Prêmio Wanda de Aguiar Horta, $1^{\circ}$ lugar, 51CBEn

${ }^{2}$ Enfermeira. Especialista em Administração da Assistência de Enfermagem em Serviços de Saúde pela EEUFMG e em Estomaterapia pela EEUSP. Mestranda da EEUFMG. Docente do ENB da EEUFMG.

${ }^{3}$ Enfermeira. Mestranda da EEUFMG. Docente do ENB da EEUFMG.

4 Enfermeira. Especialista em Administração Hospitalar. Mestranda da FAE/UFMG. Docente do ENB da EEUFMG. 
e da ferida e a indicação e manuseio das coberturas. Este protocolo estabelece um processo de limpeza que preserva a viabilidade do tecido de granulação e a utilizaçăo de coberturas interativas, as quais criam um ambiente que mantém a umidade e a temperatura, estimula a angiogênese e promove a epitelização e a contratura da ferida, como recomenda a literatura recente(Black; Jacobs, 1996, Bryan, 1992, Danis, 1992, Eaglstein, 1990, Gilmam at . al., 1985)

O setor de Estomaterapia, após a implantaçăo do protocolo, vem realizando a cicatrização das feridas em menor tempo e a custo mais reduzido. Entretanto, em janeiro de 1999, o setor de Compras dessa instituição passou a ter dificuldades na aquisição das coberturas, principalmente hidrocolóide, levantando novos questionamentos a respeito do custo do tratamento utilizado. Foi sugerido pela administraçăo do hospital o retorno ao tratamento tradicional.

O objetivo deste trabalho é comparar o custo do curativo tradicional e o do preconizado pelo protocolo do setor, nos diversos tipos de feridas.

\section{FUNCIONAMENTO DO SETOR}

O atendimento no setor de Estomaterapia é realizado por uma equipe multidisciplinar (angiologista, fisioterapeuta, terapeuta ocupacional), em que cada profissional atua na sua área especifica e o individuo é avaliado de forma holistica. Além do tratamento da ferida, são desenvolvidos trabalhos educativos que levam o paciente a perceber sua responsabilidade $e$ seu papel no tratamento e em sua reabilitação.

O setor, além de prestar assistência multidisciplinar, desenvolve atividades de ensino e pesquisa. Neste aspecto, a parceria entre o HC/UFMG e a EE/UFMG é fundamental, pois o setor funciona como campo de estudo para alunos de graduação, profissionais da área de saúde e bolsistas. Atualmente, o serviço conta com um bolsista de extensăo, aluno da graduação do curso de Enfermagem da EE/UFMG, que presta assistência aos portadores de feridas e desenvolve atividades de monitoria e pesquisa.

O serviço vem atendendo pacientes portadores de feridas crônicas no anexo de Dermatologia. Neste ano, pretende-se implantar em todo o HC/UFMG esta nova tecnologia adotada pelas enfermeiras do setor de Estomaterapia. Para isso, programou-se a capacitação dos enfermeiros do hospital através de treinamento, que tem por objetivo promover a sistematizaçăo do conhecimento e o desenvolvimento de habilidades para a utilizaçăo da nova tecnologia, com a implantação e implementação do protocolo nas unidades de internação do hospital. O treinamento de cada profissional dar-se-á no setor de Estomaterapia e terá duração minima de dois meses.

O atendimento no setor ocorre às $2^{\mathrm{a}}$ e $5^{\mathrm{a}}$ feiras, no horário de $7 \mathrm{~h} 30$ às $12 \mathrm{~h} 30$ e de $13 \mathrm{~h} 30$ às $18 \mathrm{~h} 30$. Os clientes săo encaminhados ao setor pelos médicos da Dermatologia, Angiologia, Endocrinologia e enfermeiros da unidade de internaçăo do HC/UFMG.

\section{CLIENTELA}

São atendidos pacientes de ambos os sexos, sem limite de idade, portadores de ferida crônica decorrente de insuficiência venosa, drepanocitose, seqüela de hanseniase e complicaçăo diabética. Geralmente, possuem mais de uma ferida e convivem com vários fatores sistêmicos e locais que retardam a cicatrização. O nivel socioeconômico e cultural é diversificado.

No periodo de junho/98 a janeiro/99, foram atendidos 131 pacientes, sendo que 72 foram somente avaliados e orientados sobre a melhor maneira de se cuidarem e 60 iniciaram tratamento no setor. Destes, $22(36,7 \%)$ permanecem em tratamento e acompanhamento; $30(50 \%)$ receberam alta por cura e $8(13,3 \%)$ receberam alta por năo seguirem o tratamento preconizado. Foram tratadas 150 feridas, sendo realizadas 2.206 trocas de curativos e confeccionadas 286 
botas de Unna (tratamento coadjuvante para facilitar o retorno venoso na insuficiência venosa).

\section{TRATAMENTO}

Dentre os fatores que podem facilitar ou retardar o processo de cicatrização, destacamos a forma de proceder à limpeza e o tipo de cobertura utilizada nos curativos. O objetivo da limpeza é remover a matéria estranha e reduzir o número de microorganismos. A manipulação inicial consiste na limpeza cuidadosa e rigorosa da ferida, em toda sua extensão e profundidade. A melhor técnica de limpeza do delicado leito da lesão compreende a irrigação com jatos de solução salina isotônica $(0,9 \%)$, que serăo suficientes para remover os corpos estranhos e os tecidos frouxamente aderidos. O emprego de soluções ácidas ou cáusticas é contra-indicado, uma vez que, de modo geral, esses produtos comprometem a vitalidade do tecido tissular remanescente. Deve também ser evitada a agressiva esfregaçăo da pele em volta da ferida, pois pode ocorrer traumatismo, propiciando a introduçăo de bactérias, além da destruição de sua barreira protetora.

Atualmente, vêm sendo utilizadas coberturas de hidrocolóide (Duoderm ${ }^{\star}$, Comfeel ${ }^{\star}$, Sure Skin ${ }^{\oplus}$, Tegasorb ${ }^{\circledast}$ ); alginato de cálcio (Kaltostat ${ }^{\star}$, Algoderm ${ }^{\circledast}$, Tegagen ${ }^{\oplus}$ ), padronizadas desde 1996 pelo Hospital das Clinicas; pomada colagenase a 10\% (Kolagenase ${ }^{\varpi}$ ), utilizada na instituiçăo há mais de dez anos; ácidos graxos essenciais (Dersani $\left.{ }^{\circledR}\right)$; sulfadiazina de prata e nitrato de cério (Dermacerium ${ }^{\odot}$ ); cobertura de carvão ativado e prata (Actisorb Plus ${ }^{\circledR}$ ); compressa de fibras de viscose e poliéster de baixa aderência (Melolin); e hidrogel amorfo (Intrasite-Gel ${ }^{\circledR}$ ). que estão em fase de avaliaçăo.

Dentre os curativos oclusivos, podemos citar os de hidrocolóide e os de alginato de cálcio. As coberturas de hidrocolóide possuem duas camadas: a externa, composta por película ou espuma de poliuretano (flexivel e impermeável à água, bactérias e outros agentes externos); e a interna, composta de partículas hidroativas (à base de carboximetilcelulose) e gelatina, que interagem com o exsudato da ferida, formando um gel úmido e macio. As particulas de celulose se expandem ao absorverem o exsudato e a camada impermeável isola a ferida do ar atmosférico, provocando hipóxia no leito da ferida, estimulando, assim, a angiogênese. A temperatura é mantida próxima ao valor fisiológico, ideal para o crescimento celular, e o meio úmido estimula a açăo das enzimas na remoção do tecido necrótico. Por sua vez, os leucócitos tornam-se aptos para a fagocitose e facilitam a migração de células epiteliais. As terminações nervosas umidecidas proporcionam alivio da dor e o gel reduz os riscos de danos à pele adjacente ao leito da ferida, no momento de remoção do curativo.

O curativo de hidrocolóide deve ser aplicado diretamente sobre a ferida, devendo-se ter o cuidado de deixar uma borda de 1,0 a 2,0 cm, para fixar na pele integra. Pode permanecer sem ser trocado por até sete dias, dependendo da quantidade de exsudato. A cobertura é de fácil aplicaçăo e remoçăo, e é indicada para feridas năo infectadas, traumáticas, cirủrgicas, áreas doadoras de transplante de pele, úlceras venosas, úlceras de pressão de estágio I a IV. (Eaglestein, 1990, Gilmam et al., 1985).

O curativo de alginato de cálcio contém sais naturais de ácido algimico, extraido de algas marinhas marrons. Os alginatos săo compostos que apresentam atividade hemostática e aceleram a cicatrizaçăo, propriedades conhecidas desde a década de 40 . A base desses efeitos é a formação de um gel hidrofilico sobre a superficie da ferida, o qual permite uma reação de troca iônica entre o cálcio do alginato, o sódio do sangue e o exsudato, originando um composto solúvel: o alginato de cálcio-sódio. Os ions de cálcio liberados constituem um dos fatores que auxiliarão na coagulação. Além disso, os alginatos năo săo tóxicos ou alergênicos e săo totalmente biodegradáveis, com pouca ou nenhuma reaçăo tissular.

O alginato de cálcio, além de reduzir o tempo de cicatrizaçăo, é de fácil aplicação e remoçăo. Devido à sua capacidade de absorção, reduz o número de trocas. É classificado 
como curativo primário, porque é aplicado diretamente sobre o leito da ferida, necessitando de um curativo secundário. Geralmente, utilizam-se gaze estéril e atadura ou algum tipo de adesivo, para ocluir e fixar o curativo primário, o qual pode permanecer por até cinco dias sem ser trocado. O periodo é definido conforme a quantidade de exsudato presente na ferida. Essa cobertura pode ser indicada para feridas infectadas ou não, com sangramento ou com média e alta drenagem de exsudato (Davis, 1992, Eaglstein, 1990). A permanência por tempo prolongado é uma de suas principais vantagens sobre as coberturas tradicionais, que exigem trocas freqüentes, interferindo de forma significativa no processo de cicatrizaçăo, uma vez que mantêm a temperatura ideal $\left(37^{\circ} \mathrm{C}\right)$ no leito da ferida por todo tempo. Essa temperatura faz-se necessária para ocorrer a divisăo celular, o que, uma vez diminuida, leva até três horas para alcançar o valor recomendado. (Dealey, 1996, Carnille, 1996). Outro fator interferente é o trauma ao tecido de granulaçăo, pois ao se retirar as gazes aderidas pode-se lesar os vasos neoformados, desencadeando sucessivamente a fase nflamatória do processo cicatricial. Portanto, o aumento do número de trocas implica maior risco de trauma.

O curativo de carvăo ativado e prata é uma cobertura estéril, composta de um tecido de carvăo ativado, impregnado com prata, envolto por uma camada de năo-tecido, selada em toda sua extensão. A camada de não tecido propicia o fluxo do exsudato para o tecido de carvão ativado que retém as bactérias, que são inativadas pela ação bactericida da prata (adsorção fisica de bactérias). O tecido de carvão ativado também elimina odores desagradáveis, melhorando a qualidade de vida dos pacientes.

A compressa de fibras de viscose e poliéster de baixa aderência é indicada para as feridas pouco exsudativas, com ou sem tecido necrótico. Tem-se observado uma boa resposta no desbridamento autolitico quando associado ao Hidrogel nas feridas com necrose seca (escara). O Hidrogel amorfo é um composto transparente, à base de água $(77,7 \%)$, propileno glicol $(20 \%)$ e carboximetilcelulose $(2,3 \%)$, utilizado em associação com outras coberturas para propiciar o desbridamento autolitico. Essas coberturas descritas preenchem muitos requisitos do ambiente ótimo para a cicatrizaçăo de feridas. (Eaglstein, 1990, Gilaman et al., 1985)

Os ácidos graxos essenciais (AGE) săo indicados para feridas sem infecçăo e com pequena área comprometida por tecido necrótico. Sua principal vantagem é criar um meio adequado para o desenvolvimento do processo de cicatrizaçăo, reduzindo o tempo de existência da ferida, ou seja, acelerando a cura. São encontrados sob a forma líquida oleosa, fazendo-se necessário trocas de curativos diárias, para manutençăo da umidade fisiológica no leito da lesăo.

O creme de sulfadiazina de prata e nitrato de cério tem sido utilizado no tratamento de feridas crônicas. Age como anti-séptico reduzindo o número de microorganismo no leito da lesăo, sem, contudo, inibir a proliferaçăo de fibroblasto, como a maioria das soluções antisépticas. O produto forma uma camada membranosa, gelatinosa recobrindo a ferida, supomos que este mecanismo mantém a temperatura e a umidade fisiológica necessárias para o processo cicatricial.

A pomada colagenase $10 \%$ é um produto enzimático utilizado para fazer o desbridamento químico nas feridas com tecido necrótico. O produto perde a ação 8 horas após ser colocado no leito da ferida, exigindo a confecçăo de três curativos diários. É contra-indicado para as feridas com infecçăo e deve ser utilizado por no máximo 15 dias.

\section{CUSTO DA LIMPEZA}

Na comparação do custo do curativo tradicional com o dos curativos em que săo utilizadas 
coberturas de última geração ${ }^{4}$ utilizamos os preços obtidos pelo HC/UFMG nas compras realizadas no mês de fevereiro/99. O cálculo do consumo utilizado nos procedimentos foi baseado na experiência das autoras. Tomamos por base uma ferida crônica decorrente de insuficiência venosa do membro inferior direito, com $49 \mathrm{~cm}^{2}$ de área e $0,3 \mathrm{~cm}$ de profundidade, comprometida por tecido necrótico de cor marrom, consistência amolecida e drenagem de exsudato seroso. No quadro 1 estão descritos o material utilizado na limpeza desta ferida, sua quantidade e custo por troca, tanto na técnica tradicional como na técnica atualizada preconizada no protocolo.

QUADRO 1- Custo comparativo da limpeza tradicional e limpeza atualizada - Setor de Estomaterapia do HC/UFMG, Belo Horizonte - 1999.

\begin{tabular}{|l|c|c|l|c|c|}
\hline \multicolumn{3}{|c|}{ Limpeza tradicional } & \multicolumn{3}{c|}{ Limpeza atualizada } \\
\hline \multicolumn{1}{|c|}{ Material } & Quantidade & Custo (RS) & \multicolumn{1}{c|}{ Material } & Quantidade & Custo (RS) \\
\hline Soro fisiológico 250ml & 01 & 0,37 & Soro fisiológico 250ml & 02 & 0,74 \\
\hline Luvas de procedimento & 02 & 0,10 & Luvas de procedimento & 02 & 0,10 \\
\hline Pt. gaze com 5 un. & 02 & 0,32 & Pt. Gaze com 5un. & 02 & 0,32 \\
\hline PVPI tópico & $20 \mathrm{ml}$ & 0,15 & Sabão neutro & $20 \mathrm{ml}$ & 0,03 \\
\hline PVPI degermante & $20 \mathrm{ml}$ & 0,15 & Agulha 25x 8 mm & 01 & 0,03 \\
\hline Cortoplast & 01 & 0,20 & & & \\
\hline Pacote de curativo & 01 & $\star$ & & & 1,22 \\
\hline TOTAL & & 1,29 & & & \\
\hline
\end{tabular}

* O custo do processamento deste material não foi computado porque a Central de Esterilização do HC/UFMG não dispõe do dado no momento.

O Quadro 1 demonstra que o custo unitário da limpeza atualizada é 5,4\% menor do que o da limpeza tradicional. Cabe ressaltar que o custo do processamento do pacote do curativo utilizado na limpeza tradicional não está incluído no seu custo total, o que aumentaria o custo da limpeza tradicional. Podemos observar que a diferença de custo entre ambos é de $R \$ 0,07$, considerando que o curativo tradicional exige mais de uma troca por dia, o custo da limpeza se multiplica por três, elevando o custo final do procedimento.

\section{CUSTO COMPARATIVO DO CURATIVO TRADICIONAL E DO ATUALIZADO}

Para calcular o custo do curativo, tomamos como referência a ferida já descrita, com 49 $\mathrm{cm}^{2}$ de área e $0,3 \mathrm{~cm}$ de profundidade, os materiais necessários para o tratamento no periodo de uma semana, com o respectivo número de trocas decorrente da cobertura utilizada, como demonstrado no quadro 2.

Analisando o quadro, constatamos que o número de trocas do curativo tradicional (21) chega a ser $150 \%$ maior que o do curativo preconizado (2), o que, conforme já descrito, pode interferir negativamente no processo de cicatrização. As pomadas contendo colagenase têm necessidade de serem trocadas a cada oito horas, uma vez que este é o tempo de ação da enzima. A neomicina com bacitracina também deve ser trocada a cada oito horas, pois a gaze absorve tanto o exsudato quanto a pomada, retirando-a do contato com o leito da lesão, impedindo a sua ação. O creme de sulfadiazina de prata e nitrato de cério é trocado duas vezes por dia, na ferida já descrita, em virtude do volume do exsudato, porque em feridas que apresentem um menor volume o creme pode ser trocado a cada vinte e quatro horas.

O número de trocas do curativo com sacarose está relacionado à manutenção da sua

${ }^{4}$ Curativos interativos que criam o meio adequado para ocorrer o processo de cicatrização mantendo o meio úmido, a temperatura em tomo de $37^{\circ} \mathrm{C}$, a impermeabilidade que propicia a hipóxia no leito da ferida estimulando a angiogênese, a produção do tecido de granulação, a epitelização e a maturação da ferida. 
hiperosmolaridade e do seu efeito hidroscópico e bactericida, reduzindo o edema lesional e a microbiota da lesão. Para garantir seu mecanismo de ação, faz-se necessário as trocas freqüentes do curativo, isto é, em média de cinco vezes ao dia para feridas exsudativas.

Observa-se que o custo mais alto, sem considerar aqui o custo da limpeza, foi o do curativo tradicional_com pomada de colagenase mais cloranfenicol $(R \$ 32,55)$ _, amplamente difundido nos Serviços de Saúde. O segundo custo mais alto ficou com o curativo com sulfadiazina de prata e nitrato de cério $(R \$ 29,50)$.

QUADRO 2- Consumo de material em diferentes cúrativos com respectivos custos - Setor de Estomaterapia do HC/UFMG, Belo Horizonte - 1999.

\begin{tabular}{|c|c|c|c|c|c|c|c|}
\hline Coberturs: & Moteridal p/ Trooses & Custo (RS) & $\begin{array}{l}\text { Quantidade p/ } \\
\text { trock }\end{array}$ & Cuato Trocen (RS) & $\begin{array}{c}\text { Trocas } \\
\text { semanais }\end{array}$ & Custo remanal (RS) & Cunto total (RS) \\
\hline \multirow[t]{5}{*}{ Calegenase $10 \%$ (Kolagenase') } & $\begin{array}{l}\text { Colagenase d } 30 \mathrm{~g} \\
\text { Curep }\end{array}$ & \begin{tabular}{|l|l|l|}
11,64 \\
016
\end{tabular} & $1,5 \mathrm{~g}$ & 0,55 & \multirow{5}{*}{21} & 11,55 & \multirow{5}{*}{27,30} \\
\hline & 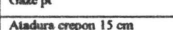 & \begin{tabular}{|l|}
, 16 \\
0,40 \\
\end{tabular} & $1=$ & 0,160 & & \begin{tabular}{|l}
3,36 \\
840
\end{tabular} & \\
\hline & Pita crepe $50 \mathrm{~m}$ & & & & & & \\
\hline & Fita ciruergica $10 \mathrm{~m}$ & $\frac{1,10}{1,24}$ & $\frac{20 \mathrm{~cm}}{20 \mathrm{~cm}}$ & $\frac{0,01}{0,03}$ & & \begin{tabular}{|l|l|}
0,21 \\
0,63 \\
\end{tabular} & \\
\hline & Creme hidratante $50_{\mathrm{g}}$ & 2,96 & 248 & 0,15 & & \begin{tabular}{|l|l|}
3,15 \\
\end{tabular} & \\
\hline \multirow{6}{*}{ 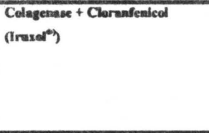 } & Iruxol ${ }^{2} / 10 \mathrm{~g}$ & 5,29 & 1,58 & 0,8 & \multirow{6}{*}{21} & 16,80 & \multirow{6}{*}{ 32,55 } \\
\hline & Geve pt & 0,16 & 10 & 0,16 & & 3,36 & \\
\hline & Atadura crepon $15 \mathrm{~cm}$ & 0,40 & $1 \mathrm{~m}$ & 0,40 & & 8,40 & \\
\hline & Fita crepe $50 \mathrm{~m}$ & 1,10 & $50 \mathrm{~cm}$ & 0.01 & & \begin{tabular}{|l|}
0,21 \\
\end{tabular} & \\
\hline & \begin{tabular}{|l|l|l} 
Fitu cinirgica $10 \mathrm{~m}$ \\
\end{tabular} & \begin{tabular}{|l|l|}
1,24 \\
, 26
\end{tabular} & $20 \mathrm{~cm}$ & 0,03 & & \begin{tabular}{|l|l|}
0,63 \\
, 46
\end{tabular} & \\
\hline & 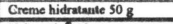 & 2,96 & $2,4 \mathrm{~g}$ & 0,15 & & 3,15 & \\
\hline \multirow{6}{*}{ 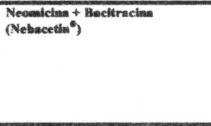 } & Nebactin $15_{8}$ & \begin{tabular}{|l|l|}
3,42 \\
016 \\
\end{tabular} & 1,58 & 0,35 & \multirow{6}{*}{21} & \begin{tabular}{|l}
7,35 \\
3,36 \\
\end{tabular} & \multirow{6}{*}{23,10} \\
\hline & Gase pt & 0,16 & 1 ш & 0,16 & & 3,36 & \\
\hline & Atedura cropon $15 \mathrm{~cm}$ & 0,40 & 1 an & 0,40 & & 8,40 & \\
\hline & Fita crape $50 \mathrm{~m}$ & 1,10 & $50 \mathrm{~cm}$ & 0,01 & & \begin{tabular}{|l|}
0,21 \\
\end{tabular} & \\
\hline & Fita cirisgica $10 \mathrm{~m}$ & 1,24 & $20 \mathrm{~cm}$ & 0,03 & & \begin{tabular}{|l|l|}
0,63 \\
\end{tabular} & \\
\hline & Creme hidratante $50 \mathrm{~g}$ & $\begin{array}{l}, 2,96 \\
\end{array}$ & $2,4 \mathrm{~g}$ & 0,15 & & $0,0,15$ & \\
\hline \multirow[t]{6}{*}{ Sacarosece } & Aphicar cristal $1 / \mathrm{Kg}$ & 0,40 & $20 \mathrm{~g}$ & 0,008 & \multirow{6}{*}{35} & 0.28 & \multirow{6}{*}{26,53} \\
\hline & Gase pt & 0,16 & 1 an & 0,16 & & \begin{tabular}{|l|}
5,60 \\
\end{tabular} & \\
\hline & $\begin{array}{ll}\text { Atodura eropon } 15 \mathrm{~cm} \\
\end{array}$ & 0,40 & 10 & 0,40 & & $\begin{array}{l}14,00 \\
14,00\end{array}$ & \\
\hline & Fits crepe $50 \mathrm{~m}$ & 1,10 & $50 \mathrm{~cm}$ & 0,01 & & 0,35 & \\
\hline & \begin{tabular}{|l} 
Fita ciriurgica $10 \mathrm{~m}$ \\
\end{tabular} & $\frac{1,24}{1.24}$ & $20 \mathrm{~cm}$ & 0.03 & & 1,05 & \\
\hline & Creme hidratante $50 \mathrm{~g}$ & 2,96 & $2,4 \mathrm{~g}$ & 0,15 & & 5,25 & \\
\hline \multirow{6}{*}{ 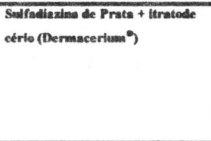 } & Demmacerium? $\mathrm{SOg}^{2}$ & 19,00 & $3,5 \mathrm{~g}$ & 1,35 & \multirow{6}{*}{14} & 19,00 & \multirow{6}{*}{29,50} \\
\hline & Gaze pt & 0,16 & $1 \mathrm{~m}$ & 0.16 & & 2.24 & \\
\hline & Aledsura crepon $15 \mathrm{~cm}$ & 0,40 & $1 \mathrm{~mm}$ & 0.40 & & 3.60 & \\
\hline & Fita crepe $50 \mathrm{~m}$ & 1,10 & $50 \mathrm{~cm}$ & 0,01 & & \begin{tabular}{|l|}
0,14 \\
\end{tabular} & \\
\hline & Fita Cinirgica $10 \mathrm{~m}$ & 1,24 & $20 \mathrm{~cm}$ & 0.03 & & \begin{tabular}{|l|}
0,42 \\
\end{tabular} & \\
\hline & Creme hidratante $50 \mathrm{~g}$ & 2,96 & 2,48 & 0,15 & & 2,10 & \\
\hline \multirow[t]{5}{*}{ AGE (Derrean ) } & AGE 200mal & 23.00 & $7 \mathrm{ml}$ & 0,81 & \multirow{5}{*}{14} & 11,34 & \multirow{5}{*}{21,82} \\
\hline & Geare pt & 0,16 & 10 & 0.16 & & 2,24 & \\
\hline & Aledura crepon $15 \mathrm{~cm}$ & 0,40 & 10 & 0,40 & & \begin{tabular}{|l|l|}
5,60 \\
\end{tabular} & \\
\hline & Fita corpe $50 \mathrm{~m}$ & $\frac{1,10}{296}$ & $50 \mathrm{~cm}$ & 0,01 & & \begin{tabular}{|l|l|}
0,14 \\
2,0
\end{tabular} & \\
\hline & Cremie hidratante $50 \mathrm{~g}$ & 2,96 & $2,4 \mathrm{~g}$ & 0,15 & & 2,10 & \\
\hline \multirow{6}{*}{$\begin{array}{l}\text { Fibras de viseose + Postiester } \\
\text { (Melolias") }\end{array}$} & Melolin $10 \times 10 \mathrm{~cm}$ & $\frac{1,72}{1,60}$ & $\mid \mathrm{pl}$ & 1,72 & \multirow{6}{*}{2} & \begin{tabular}{|l|l|}
3,44 \\
\end{tabular} & \\
\hline & Hidrogel $25_{8}$ & 36,00 & $0.13 \mathrm{~g}$ & 0,19 & & 0,38 & \\
\hline & Atadura cropon $15 \mathrm{~cm}$ & 0,40 & 10 & 0,40 & & 0,80 & 5,00 \\
\hline & Fita crepe $\mathbf{S 0} \mathbf{~ m}$ & 1,10 & $50 \mathrm{~cm}$ & 0,01 & & 0,02 & \\
\hline & Fita cirírgica $10 \mathrm{~m}$ & 1,24 & $20 \mathrm{~cm}$ & 0,03 & & 0,06 & \\
\hline & Creme hidratante $50 \mathrm{~g}$ & 2,96 & $2,4 \mathrm{~g}$ & 0,15 & & 0.30 & \\
\hline Hidrocecoloside (Sare Skikn"? & Hidrocolloide $10 \times 10 \mathrm{~cm}$ & 12,50 & $\frac{1 p^{1}}{1 l^{2}}$ & 12,50 & & 25,00 & \\
\hline Dedermee, Comfeet", Tegasorst" & Hidrocololóde po $6 \mathrm{~g}$ & 9,18 & $0,03 \mathrm{~g}$ & 0,05 & & 0 & \\
\hline - & Aledura crepon $15 \mathrm{~cm}$ & 0,40 & $1 \pm$ & 0,40 & 2 & 0,80 & 20,28 \\
\hline & Fita crepe $50 \mathrm{~m}$ & 1,10 & $50 \mathrm{~cm}$ & 0,01 & & 0,02 & \\
\hline & 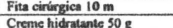 & $\frac{1,24}{2.96}$ & $\frac{20 \mathrm{~cm}}{24 \mathrm{~g}}$ & $\frac{0,03}{0,15}$ & & \begin{tabular}{|l|l}
0.06 \\
0.30
\end{tabular} & \\
\hline Alginato de caliclo (Kaltontar?, & Alginato de chlcio $20 \times 10 \mathrm{~cm}$ & $\frac{22,11}{22,11}$ & $\frac{2.4 \mathrm{~B}}{1 / 2 \mathrm{pl}}$ & $\frac{0,19}{11,00}$ & & $\frac{0,30}{22,11}$ & \\
\hline Algoderm", Tegagen" & Geseopt & 0,16 & $1 \mathrm{~m}$ & 0,16 & Priminio & 1,12 & \\
\hline & Atedura creponi $15 \mathrm{~cm}$ & 0,40 & $1 \mathrm{~m}$ & 0,40 & $\begin{array}{l}\text { Secumderio } \\
\text { Ser) }\end{array}$ & 0.80 & 25,93 \\
\hline & Fits crepe $50 \mathrm{~m}$ & 1,10 & $50 \mathrm{~cm}$ & 0,01 & (05) & 0,07 & \\
\hline
\end{tabular}

O Quadro 2 demonstra que a utilização das coberturas preconizadas pelo protocolo do sso serviço não aumenta os custos dos procedimentos. A utilização de algumas delas reduz drasticamente esses custos, como é o caso das coberturas com fibras de viscose mais poliéster.

\section{CUSTO TOTAL DO PROCEDIMENTO: TRADICIONAL E PRECONIZADO}

O custo total do procedimento, obteve-se somandoo custo da limpeza e o dos materiais usados nas diversas coberturas. A partir dos quadros 1 e 2, estruturamos o Quadro 3. 
QUADRO 3- Custo comparativo do procedimento tradicional e do procedimento atualizado em diversas feridas - Setor de Estomaterapia do HC/UFMG, Belo Horizonte - 1999.

\begin{tabular}{|c|c|c|c|c|}
\hline \multirow[t]{2}{*}{ Tipo de Ferida } & \multirow{2}{*}{$\begin{array}{l}\text { Curativo } \\
\text { tradicional }\end{array}$} & \multicolumn{3}{|c|}{ Custo semanal } \\
\hline & & Limpeza & Cobertura & Total \\
\hline \multirow{3}{*}{$\begin{array}{c}\text { Com } \\
\text { infecçãa }\end{array}$} & Iruxol $^{2}$ & 27,90 & 32,55 & 60,45 \\
\hline & Sacarose & 45,15 & 26,53 & 71,68 \\
\hline & Nebacetin ${ }^{\otimes}$ * & 27,90 & 23,10 & 51,00 \\
\hline Sem infecção & Colagenase $10 \%$ & 27,90 & 27,30 & 55,20 \\
\hline \multirow{2}{*}{$\begin{array}{c}\text { Com } 80 \% \text { de } \\
\text { necrose }\end{array}$} & Colagenase $10 \%$ & 27,90 & 27,30 & 55,20 \\
\hline & Iruxol $^{\otimes}$ & 27,90 & 32,55 & 60,45 \\
\hline Sem necrose & Nebacetin & 27,90 & 23,10 & 51,00 \\
\hline Tipo de Ferida & $\begin{array}{c}\text { Curativo } \\
\text { preconizado }\end{array}$ & Limpeza & Cobertura & Total \\
\hline \multirow[t]{2}{*}{ Com infeçåo } & Carvão + prata & 2,44 & 28,82 & 31,26 \\
\hline & $\begin{array}{l}\text { Alginato de } \\
\mathrm{Ca}^{++}\end{array}$ & 2,44 & 25,93 & 28,37 \\
\hline \multirow{4}{*}{$\begin{array}{c}\text { Sem } \\
\text { Infecção }\end{array}$} & Melolin & 2,44 & 5,00 & 7,44 \\
\hline & Hidrocolóide & 2,44 & 26,28 & 28,72 \\
\hline & Dermacerium & 17,08 & 29,50 & 46,58 \\
\hline & $\mathrm{AGE}$ & 17,08 & 21,82 & 39,90 \\
\hline \multirow{3}{*}{$\begin{array}{l}\text { Com } 80 \% \\
\text { de necrose }\end{array}$} & Hidrocolóide & 2,44 & 26,28 & 28,72 \\
\hline & Melolin & 2,44 & 5,00 & 7,44 \\
\hline & $\begin{array}{l}\text { Alginato de } \\
\mathrm{Ca}^{++}\end{array}$ & 2,44 & 25,93 & 28,37 \\
\hline \multirow[t]{3}{*}{ Sem necrose } & Melolin & 2,44 & 5,00 & 7,44 \\
\hline & Hidrocolóide & 2,44 & 26,28 & 28,72 \\
\hline & $\mathrm{AGE}$ & 17,08 & 21,82 & 39,90 \\
\hline
\end{tabular}

*No curativo tradicional, respeitamos o tratamento que geralmente é utilizado na instituiçăo.

O Quadro 3 demonstra que o custo final dos curativos em que se utilizam as novas coberturas, que exigem um menor número de trocas semanais, é bem inferior ao custo final dos curativos tradicionais. Observa-se que o grande diferencial dos custos verifica-se principalmente na limpeza, que se eleva bastante no curativo tradicional, em função do número de trocas. Nossa experiência permite apontar ainda uma significativa diminuiçăo dos custos do tratamento preconizado, em decorrência da reduçăo do tempo necessário para a cura e da otimizaçăo das horas de trabalho dos profissionais de saúde.

O protocolo do setor de Estomaterapia do $\mathrm{HC}$ preconiza o uso apropriado de coberturas para cada tipo de ferida, exceto para a ferida com infecção, cuja opção única ainda é o alginato de cálcio. Essa diversidade é necessária, porque nem as feridas com características semelhantes respondem da mesma forma ao tratamento, não sendo possivel padronizar somente o tratamento preconizado de menor custo. Outro dado a ser considerado é que alguns tratamentos săo eficientes em determinada fase do processo de cicatrizaçăo e em determinadas doenças de base, necessitando haver modificaçőes das coberturas utilizadas no decorrer do tratamento. A indicação do tratamento não está subordinada a regras objetivas, à medida que o ser humano tem respostas individuais que o profissional năo consegue detectar. Por exemplo, feridas com as mesmas características em pacientes diferentes podem responder ao mesmo tratamento de forma totalmente diferente. A habilidade em reconhecer a necessidade de mudança na indicaçăo das coberturas é adquirida com o conhecimento científico e a experiência na assistência a portadores de feridas. 


\section{CONSIDERAÇŌES FINAIS}

As autoras, tomando por base os dados obtidos quando da comparaçăo do custo do curativo tradicional com o preconizado pelo setor de Estomaterapia, constataram que o custo da limpeza atualizada (preconizada pelo protocolo do serviço) é $5,4 \%$ menor que aquela da tradicional, ressaltando que o número de trocas foi desconsiderado, bem como o custo do processamento do pacote do curativo. As coberturas padronizadas năo elevam o custo do tratamento de feridas crônicas, chegando em algumas situaçōes a ocorrer diminuição significativa (81\%). É possivel afirmar que o custo final do curativo preconizado pelo protocolo é inferior ao do tradicional e que a frequência na troca do curativo tradicional é o fator de maior significância na elevação de seu custo.

As autoras recomendam que, ao escolher ou indicar um tratamento, sejam levados em consideração os seguintes fatores: condiçōes que favoreçam o processo de cicatrizaçăo; frequência de troca, custo gerado pela limpeza e coberturas indicadas.

ABSTRACT: This study compares the cost of traditional wound dressing and the one commended by HC/UFMG Stomotherapy sector's protocol for several kinds of wounds treatment. We finaly concluded that the cost of the latter is inferior to the first, and the it is the frequency in changing the dressings that appoint a greater significance factor in the increasing of the price.

KEY WORDS: wounds, cost, dressing, cleasing, covering.

RESUMEN: Este estudio compara el coste del curativo tradicional y el del preconizado/propuesto por el protocolo del sector de Estomaterapia del HC/UFMG en el tratamiento de diversos tipos de heridas. Al final del trabajo se pudo concluir que el coste del último es inferior al primero y que la frecuencia en el cambio del curativo tradicional constituye factor de mayor significancia para elevar su coste.

PALABRAS CLAVE: heridas, coste, curativo, limpieza, cobertura.

\section{REFERÊNCIAS BIBLIOGRÁFICAS}

BLACK, J.M; JACOBS, E.M. Luckmann \& Sorensen. Enfermagem médico-cirürgica, uma abordagem psicofisiológica. 4 ed., Rio de Janeiro: Guanabara Koogan, 1996. v.1, 1050p.

BRYANT, Ruth A. Acute and chronic wounds. St. Louis: Mosby Year Book, 1992. 350p.

CARVILLE, Kerlyn. Evaluación individual de los heridas. Helios, Dinamarca, v.4, n.3, 11-14p., 1996.

DAVIS, Margery $\mathrm{H}$. et al. The wound programme. Londres: Center for Medical Education, 1992. 188p.

DEALEY, Carol. Cuidando de feridas: um guia para enfermeiras. São Paulo: Atheneu, 1996.

EAGLSTEIN, W. et al. New Directions in wound healing. 5 ed. New Jersey, 1990. 180p.

GILMAN, A.G.; GOODMAN, L.S.; RALL, T.W.; MURAD, F. Goodman \& Gilman. As bases farmacológicas da terapêutica. 7. ed. Rio de Janeiro: Guanabara Koogan, 1985. p.625-626.

MARTINS, T. et al. Tratamento de feridas. Nursing, Lisboa, n. 100, p.30-37, maio 1996. MOCH, D., SCHEWE, T.; KÜHN, H.; SCHMIDT, D.; BUNTROCK, P. The linoleic acid metabolite $9 D_{s}$ hydroxy - 10,12 (E,Z) - octadecadienoic acid is a strong proinflammatory mediator in an experimental wound healing model of the rat. Biomed, Biochim, Acta 49 n. 4, 201-207, 1990.

PROTTEY, C. Investigation of functions of essential fatty acids in the skin. British Joumal of Dematology. n.97, p. 29-36, 1977. 